\title{
1 Ageing and Care in the Visual Field
}

\section{The Photography of Martine Franck}

\author{
Shirley Jordan
}

What can photography tell us about ageing and our attitudes to it? What are the conditions necessary for breaking ageist paradigms in the visual field? And how can photography depict - and promote - an ethics of care? This chapter focuses on such questions by bringing to prominence the extraordinary body of work on ageing produced by Belgian-born humanist photographer Martine Franck (1938-2012). One of the few women photographers of her generation to gain an international reputation, Franck produced an extensive body of photographs dedicated to documenting the lives of older, often marginalised people, in both domestic and institutional environments, in France and elsewhere in the world. These images have received no serious critical attention, yet arguably they occupy a significant place in the history of gerontology. They also provide a rich opportunity to re-consider the phenomenology of the photograph and the photograph's potential as a hospitable communicative field and promoter of care within the broader terrain of visual gerontology.

This chapter focuses closely on Franck's first photo book on ageing, Le Temps de vieillir: Journal d'un voyage [The Time to Grow Old: A Travel Diary] (1980), which turns ideas of journeying and discovery to original purposes. ${ }^{1}$ The chapter analyses Franck's practice in light of arguments made by age studies pioneer Margaret Morganroth Gullette, whose wryly titled Ending Ageism or How Not to Shoot Old People asks how photography might help to promote an "anti-ageist gaze" (27). It suggests an implicit dialogue set up by Franck with French existentialist philosopher Simone de Beauvoir's seminal La Vieillesse [The Coming of Age] (1970), notably regarding a shared critique of the lack of adequate social care in France and condemnatory portrayals of state-run nursing homes in the mid- to late-twentieth century. It also examines Franck's practice through a lens of contemporary care theory. Franck sets out the impetus for her project as a fundamental engagement with one of the most pressing dilemmas of our lived experience: "I wanted to find out why old age is 'disturbing' and how people are differently affected by the fact of ageing” (Le Temps 9). Here I assess her achievements in bringing

DOI: $10.4324 / 9781003058618-2$ 
us to look differently at older people and examine how she seeks to establish, through her practice of documentary and portrait photography, an ethics of care.

\section{Martine Franck: Photography as Care}

Ageing and old age were a core concern in Franck's work from the 1970s onwards. It will be helpful to begin our exploration with some general points about this unusual photographic preoccupation. Over thirty years and in hundreds of powerful images, Franck used her camera to probe the social conditions of ageing and the phenomenology of the daily lives of older people from many walks of life. She made photographs of them in their domestic environments, in institutions, in social gatherings and alone, providing challenging and memorable images which tackle unrelentingly the many-facetted nature of marginalisation. Not least of these facets was - and arguably remains - the special visual problem that society has made of older people, who struggle for legitimacy in the visual repertoire. Franck's distinctive work interrogates that problematic in ways that remain imperative today and seeks to draw the spectator in to share her position of resistance and concern.

Franck's work on ageing marked out the singularity of her vision within the male-dominated Magnum photographic agency of which she was a member, raising the issue of what care theorist Sandra Laugier refers to as the "gendered hierarchy of the objects of intellectual research" (217). More specifically, I contend, Franck saw photography as an opportunity to foreground an ethics of care and this position allows us to make an argument for the place of the camera within the evolution of feminist care theory. If the ethics of care as currently theorised "emphasises the importance of context, interdependence, relationships, and responsibilities to concrete others" (Koggel and Orme 1) then care was, as we will see in my close analyses of Le Temps de vieillir later in this chapter, clearly the driver of her practice. ${ }^{2}$ In sharp contrast to her photographer husband Henri Cartier-Bresson, who favoured the anonymity of street photography and enjoyed snatching images on the hoof, Franck's concentrated and sensitive focus on selected individuals and groups relied instead on an ethos of exchange, consistent with Carol Gilligan's contention that for women, "the logic underlying an ethic of care is a psychological logic of relationships" (In a Different 73). ${ }^{3}$ While, like all photographers, Franck might take advantage of serendipity, her default position was to seek to understand people and phenomena in depth and over time. Photography, a technology so readily associated with objectification, plunder and possession, was conceptualised by her in a quite different way. She referred to the camera as an obstacle, "a barrier that one is constantly breaking down, so as to get closer to the subject" (Baring 1). Pursuing this idea of the barrier in dialogue with John Berger, she notes: "To cross to the 


\section{Shirley Jordan}

other side, you can only get there by momentarily forgetting yourself, by being receptive to others; hence, as a photographer, I am in two different worlds at once" (One Day 13). These ideas of crossing, enhanced receptivity and straddling worlds provide an important insight into how Franck's camera was implicated in care.

Franck's photographs of older people offer the most arresting instances of how her documentary drive, her fascination for photography as meeting place and her sustained ethical practice come together as care. These images characteristically hover between social documentary shots, portraits and what Mark Edward Harris in a study of the travel photo essay calls "environmental portraits": that is, "photographs of a person in a location or scene that relates to who they are or what they do" (18). The issues underpinning recent scholarship in cultural and feminist gerontology - that ageing is an ontological blind spot; that the old are kept on the periphery of our field of vision; that ageing is in excess of what we are willing to imagine (both in general and for ourselves); that it is subject to a special kind of denial determined by what Kathleen Woodward in "Performing Age" calls "the youthful structure of the look" (162); and that older people, and perhaps especially older women, have no easy place in visual culture and are readily erased ${ }^{4}$ - were informing Franck's work long before they came to prominence in contemporary cultural gerontology. She was, then, ahead of her time, exploring the lives of older people against a backdrop of near-invisibility in a society dominated by the youth culture that exploded in the 1960s and certainly not buoyed up in her project by the kind of surge in interest in ageing that has marked our entry into the twenty-first century. Her interest in the lives of older people led to a lengthy relationship, beginning shortly after publication of Le Temps de vieillir, with the charitable association Les petits frères des Pauvres [The Little Brothers of the Poor] whose work with older people she supported and documented. ${ }^{5}$ The association reserved a privileged place for photographers in their midst, as a means not only of spreading the news about their activities but, more radically, in service of the ambition to bring about a shift in society's relationship to older people. In the tradition of social documentary, then, the camera was clearly seen by Franck as a tool for social change with radical potential. More than this, however, it became in her hands the instrument whereby the spectator is intimately challenged to interrogate the entire premise of their relationship to old age. What is especially remarkable is not so much Franck's rationale for capturing the lives of older people but the quality of her attentiveness.

Inherent in each of Franck's images is a tender, patient back story. Each tells us something about her practice of establishing relationships, waiting, listening, and fostering respect and reciprocity; indeed, one might argue that her photographs are not "taken" but rather "made." They ask to be considered within an extended time frame, not just as a moment 
frozen in time, but as what Geoff Dyer has referred to as photography's "ongoing moment." Franck's images are at once a residue, and a promoter, of the relationality that is her true goal. This shift in appreciation is critical for it takes us to the heart of the troubled ethics of photography, especially where vulnerable human subjects are concerned. Franck's images record and provoke encounters and create contemplative spaces intended to encourage the viewer to think beyond the confines of their own age-bound horizon. Above all, each is attuned to the most prominent argument in the recently emerged raft of care theory: that care ethics require heightened receptivity to vulnerability. According to Laugier, the "first tenet" of an ethics of care is that "the human is vulnerable" (219), and it is on this terrain that the encounter between photographer, spectator and subject is forged by Franck. Care, defined as a "response appropriate to the other, according to circumstance" and necessitating "an experimental attitude, a sensibility to the situation and the ability to improvise" (226; original emphasis) seems an excellent fit with Franck's practice as she photographs older people. Further, as her work develops beyond Le Temps de vieillir, Franck increasingly seeks to capture the activity and agency of care and to interrogate what Lisa Baraitser has called the "historical material conditions and institutional arrangements that enable the process of caring for, and caring about each other and the world" (14).

\section{Le Temps de vieillir: Journal d'un voyage}

Le Temps de vieillir is the first of Franck's photo books to address the subject of ageing. It constitutes a landmark in the photographer's career in as much as it announces the centrality of gerontology to her project, sows the seeds for further collaborative and solo productions related to older age and begins to interrogate the socially constructed nature of looking at other age groups. While the photographs collected in the book were put on show outside its pages, ${ }^{6}$ the book's impact is undoubtedly different from that of the gallery exhibition. Its specificity lies in its intensive interrogation of the reader's learned patterns of looking at older people and its concentrated effort to open further avenues in an essential area of social and cultural enquiry which had begun to gain new prominence in France.

Le Temps de vieillir is an idiosyncratic and complex volume whose ideologically motivated structure gradually becomes apparent as we leaf through its pages. It is best considered as a photo essay, that is, a set of photographs intended to be viewed and to produce its effect as a whole and to create a series of emotions in the viewer. It is intent on social critique, on bringing sharply to public awareness the inequalities of ageing at a moment when ageing and old age were being addressed with new intensity in France. It is also intent on exploring 
what the conditions might be for ageing well. One of its peculiarities is that it was commissioned for a series of photography books. Entitled "Journal d'un voyage" [Travel Diary], the premise of this series was to afford selected photographers free rein to make and to document a journey that they had longed to undertake. When the series editor, Daniel Filipacchi, invited Franck to contribute, he had in mind the photographer's powerful landscape images such as those in her recent book on the Lubéron region of France (Les Lubérons). Instead, Franck seized the opportunity for a metaphorical journey, via sixty-four photographs taken between 1967 and $1980^{7}$ in which she would attempt to explore the gulf that, as she saw it, separated older people from the flow of the everyday world. In accepting to incorporate Franck's project in his series, Filipacchi was prepared to take on the production of a book whose subject matter condemned it to commercial failure, for while Franck's portraits were of interest to fellow photographers, there was then no market for this kind of project. Franck herself noted the uncomprehending or even hostile reactions that her subject matter provoked: "I very rapidly noticed, in fact, that people prefer to pass over the subject of old age in an embarrassed half-silence or dodge it with quips such as: 'Why photograph old men rather than babies?'” (Le Temps 9). Filipacchi's courageous decision resulted in the publication of a work which may now be read as a powerful landmark in the history of visual gerontology.

Let us return for a moment to the trope of the travel diary. While Franck's photographs in Le Temps de vieillir do involve travel in as much as they range widely across cultures, including China, India, Japan, the UK and the USA, the trope of the journey is most consistently applied metaphorically to the idea of old age constituting an undiscovered country. Franck, who was just over forty when the volume was produced, was keen to explore an idea which continues to thread through ageing studies, that of the "unreachability" of people in later life and the untranslatable nature of their experience: what kinds of meeting can be forged across this gulf? At the same time, however, Franck's project interferes with preconceptions of unreachability, since a photographic travel diary is by definition structured by the excitement of serial encounters, by an a priori fascination for otherness on the part of the voyager and by a sustained contemplation about difference and similarity as photographer and subject are momentarily conjoined - often in mutual scrutiny and ideally in hospitality - via the lens. Ideally, rather than having their preconceptions confirmed, the traveller instead discovers what they did not know to be there. Using the idea of the traveller's gaze and its framing of cultural others to think about intergenerational encounters proves, then, to be a cannily suggestive move, one with the potential to jolt reflection about preconceived notions of age-based difference in spectators both older and younger. 
The terms of encounter that are woven into the photo essay's cover image launch Franck's interrogation of looking - in both directions across the generational divide. Her establishing shot seeks gently yet persistently to have us interrogate how we look, where we look, what we see and what we do not. It shows an anonymous, older woman visitor to an exhibition of Belgian art in Paris's Grand Palais in 1972. She is bending to peer over her spectacles at the title of a Surrealist painting by Martine Delvaux. Above her in the painting, three identical naked young women walk implacably, one behind the other, towards the surface of the canvas, their bodies illuminated by moonlight, in stark contrast to her own body which is hunched and hidden by its thick coat. The woman thus "leans in," as Franck puts it, "towards youth" (Le Temps 82). Franck sets us off here with a rich and wry allegory not only about the passage of the years, about anticipation and memory and about the regulation of women's bodies in Western art, but also about not seeing and about missed intergenerational encounters: though youth and age lean towards each other in this image, there is no exchange of gazes, no entering of each other's world. Though the young woman at the front of the painting seems to look out beyond its surface to examine what she will become, the older woman who stoops outside the frame is otherwise absorbed. There is no meeting here, just isolated acts of scrutiny.

Before Franck lets us loose on her other photographs, she invites us to contemplate a dense array of preparatory material, a jumble of images, quotations, clichés and myths related to a spectrum of positions on older people and later life. First comes a double-page scrapbook crammed with roughly cropped details from iconic paintings and photographic portraits and constituting a miniature visual essay in its own right (Le Temps 4-5). Each fragment is captioned in Franck's scribbled hand, giving us the title, date and artist or photographer. On the left-hand page cluster reminders of art historical conventions which, as Michelle Meagher notes in "Art, Ageing and the Body," "so often link the old body with, on the one hand degeneration and death, and on the other hand wisdom and self-reflection" (85). We are shown a detail from Piero della Francesca's poignant Death of Adam (c. 1466); Rembrandt's pitiless self-appraisal in his unfinished Self-Portrait with Beret (c. 1659); Frans Hals's austere, yet charitable, Woman Regents (c. 1664); and Goya's terrifyingly patriarchal caricatures of crones, Las Viejas (c. 1808), scrutinising themselves in a looking glass for residues of sexual attractiveness. On the right-hand page, as if to draw attention to the differential power of the medium, are photographs. Franck selects Félix Nadar's mesmerising portrait of his grey-haired mother; Edward Sheriff Curtis's powerful study of a wrinkled Chinook woman; a portrait of astronomer John Herschel, by Julia Margaret Cameron; ${ }^{8}$ Leonard Freed's picture of an older German couple visiting the grave of their son; and Cartier-Bresson's photograph of two semi-naked Balinese women - one young and one in later life - standing 
in the bustle of a street market. Franck's collage primes us: how have Western art and photography mediated the experiences of old age? What have they told us about it? How have they situated spectators across age groups in relation to later-life experience?

There follows Franck's short diary (Le Temps 9-16). Here, her page is split. On the left-hand side is an account of and rationale for her project; on the right, a rich compilation of literary quotations related to ageing from classical authors such as Victor Hugo, Marcel Proust and William Shakespeare. The most frequently quoted work in this section is Simone de Beauvoir's La Vieillesse, a ground-breaking study which deals with the issue of ageing at a time of prevalent marginalisation and devaluation of older people in Western industrialised societies. Here, Franck readily reveals her indebtedness. Selected quotations highlight the social and economic inequalities that mark later life; the variable construction of old age across cultures; the meaning (or lack of meaning) attributed to late life; and the dwindling of respect for experience in a technocratic society which sees age as a falling-off and a failing, and which prioritises instead the values associated with youth.

\section{A Dialogue With Simone de Beauvoir}

One of the ways in which we may productively frame Franck's ongoing project on ageing, both in and beyond Le Temps de vieillir, is by reading it alongside $L a$ Vieillesse. This is an important critical gesture. I contend that Le Temps de vieillir, published ten years after Beauvoir's remarkable and angry study, sets up an intricate dialogue with the author of La Vieillesse that goes well beyond the un-glossed quotations I have just alluded to and that implicitly responds to the philosopher's injunction to her reader to break the conspiracy of silence that sweeps the problems of ageing to the margins and facilitates the unproblematised dehumanisation of older people. Franck and Beauvoir were not close contemporaries - there are thirty years between them - but they were working at the same time, and their projects overlapped. ${ }^{9}$ La Vieillesse was published when Beauvoir was sixty-two and contending, sometimes bitterly, with her own ageing as a woman; Franck, thirty-two at that moment, was already busy taking photographs of older people and showing deep ethical interest in their lives as well as indignation about social neglect. The energy, determination, scope and focus of their respective projects on ageing bear comparison. Like Beauvoir, Franck is bent on making visible via a thoroughgoing investigation what goes unseen. Unlike Beauvoir, who notoriously recoils with horror and loathing in the face of ageing, not least her own (she speaks in La Force des choses of ageing as a scandal, a violation and a monster crouching on her chest as she sleeps), ${ }^{10}$ Franck is driven not by an overriding sense of alienation but by an instinctive, empathic curiosity. 
Franck's preface raises some of the key issues regarding unequal ageing that structure $\mathrm{La}$ Vieillesse, such as social class and poverty, how gender influences experiences of ageing, capitalism's routine discarding of workers who have outlived their usefulness and the provision of care, both in the home and in institutions. She was familiar with an important report of 1962, the Rapport de la Commission d'étude des problèmes de la vieillesse [Report of the Commission for Study of the Problems of Old Age] which argued that caring for older people in their own homes, allowing them to stay there as long as possible and keeping them integrated in the community should be public policy priorities. Her photographs - as we will see - contribute explicitly to making that argument. Franck and Beauvoir were both fascinated too about how different cultures treat older people. Though Franck's main focus is on France, her definition of old age as "a biological and social fact which depends on how the individual is treated by the collectivity" (Le Temps 15) leads her to draw together photographic evidence from a range of far-flung places and to make comparative observations. Thus:

[t]he status of 'old people' is a crude reflection of the society in which they live. The artificial segmentation of Western societies into age brackets opens the door to generational segregation. Let everyone manage as best they can; personal and family responsibility is fraying away. It seems to me that this is connected to life in cities. In the countryside and in Eastern countries older people retain genuine roles and are not brutally cast aside. Their contribution is considered, not only their cost to society. Old age seems to me less harrowing there because, generally speaking, it is not accompanied by a brutal cessation of activity.

(ibid. 12)

Towards the end of her diary Franck notes the efforts that have been made in France in recent years and praises, for instance, the Centres de l'âge d'or [Golden Age Centres] which organise meals, coach trips, slide shows and so forth, but adds: "These activities cannot fill the gulf of segregation between ages, or replace the social function that any older person could have" (ibid. 15). She argues for a viable, active place for older people, highlights the abruptness of retirement that strips individuals of their sense of identity and leaves them project-less, admires the Swedish model and its flexible, comprehensive state support (also spoken about at length by Beauvoir) (ibid. 13) and calls upon younger people to mobilise and press for a change of attitude.

While Franck's staple observations in her diary are similar to those of Beauvoir, her medium and mode of knowledge production are, of course, different. Where the tight arguments and superabundance of factual material in Beauvoir's 600-page La Vieillesse require intellectual involvement, 
Franck's photo essay is a series of raw encounters that constitute prompts to do our own thinking, to confront the crisis of looking in which older people are enmeshed and, critically, to feel. It is as though Franck seized on Beauvoir's reiterated complaint about the numerous ways in which society colludes in ensuring the invisibility of old age - a willed invisibility so naturalised that it is itself invisible - and sought to tackle it precisely through a visual project, one that challenges us to meet ageing head on not through reading about it, but through encounters which are more direct because they are visual. Even though, as Gullette observes, "ageism is not solely a visual pathology," what she calls the "social optic" nonetheless performs "several kinds of dirty work in hypervisual, bodyfocused societies" (23) and does so intensively, especially in photography. When it comes to ageing, then, and to the all-too-ready objectification of older people, the photograph, one of society's primary instruments of self-knowledge, which both constructs and records meaning, is especially good to think with.

\section{The Photograph in Visual Gerontology}

Art historian W. J. T. Mitchell's ever-useful prompt to ask ourselves "What do pictures want?" takes on a sharply new relevance with regard to the photograph in visual gerontology and ideas of responsible looking. Here arise a number of questions that are specifically pertinent to Le Temps de vieillir: what can photography do in tackling perceptions of ageing? What does an anti-ageist photograph look like? How might the multiple gazes circulating in and generated by the photograph, which between them negotiate its meaning, break the cyclical reproduction of, and collusion in, ageist ideologies? Let us turn briefly to examine Gullette's ideas about photographic counter-practices. The images that she praises for not "shooting old people" offer distractions from the idea of oldness, elude the prevailing declinist imagery and push ageing into the "second tier" (42) of our consciousness so that it is overwritten by something else. They invite us to linger, surprising and even delighting us as they challenge preconceptions about later life and bring us to gloss oldness differently. While the selection of photographs that she curates for us dates from the mid-twentieth century, she observes that the early twenty-first century in particular "may be a propitious time in portraiture of the old" (27) and her choices lean towards experimental art photography. She is enthused by the monumental photographic portraits, so surprising and arresting in their scale and context, that contemporary French urban artist JR pastes onto a host of unlikely urban surfaces in his famous Wrinkles of the City projects (2008-2015), prompting passersby in global cities to ponder age, the ageing process and how they affect the identity of both people and place. She explores at length Jeff Wall's The Giant (1992) in which a statuesque nude older woman, digitally 
enlarged so that she dominates the vast space of a public library, seems bizarrely invisible to those around her. It is true that the visual conceits and suppleness of digital image-making and novel forms of display can do remarkable things in getting us to think afresh about ageing, jolting us and re-framing questions with tremendous impact: the imaginaries of ageing projected by Gillian Waring and Cindy Sherman, with their prosthetics and knowing digital self-transformations, come to mind..$^{11}$ But I wonder whether Gullette is in danger of replicating what Davis refers to as "the gerontological assumption that the most effective way to combat societal ageism is to flood the cultural sphere with unreservedly 'positive' images of older people" (61).

Franck's documentary emphasis and analogue technology make her corpus very differently nuanced, and she has her own way of threading through visual gerontology's minefield. One of Gullette's concerns that is relevant to Franck, however, is precisely that photographic collections devoted to the theme of old age are inherently reductive; that they homogenise, carelessly lumping together older people like so many tools with which to think through part of the human condition, rather than presenting them as interesting subjects in their own right. "[B]eing asked to page through a series," claims Gullette, "weakens each solo image" (28-9). It is important to examine how Le Temps de vieillir stacks up against such a charge. First, the sheer breadth and diversity of Franck's photographs in terms of the cultures, situations and walks of life represented point against homogenisation. Her anti-declinist stance and keenness to depict what it means to age well give rise to engaging, uplifting and distinctive photographs, ranging from veteran runners in the annual Figaro cross-country run in the Bois de Boulogne (1979) to older women enjoying a game of bowls in Worthing (1980). A dermatologist whose practice in Paris is still going strong even though she is over 80 (1980), a man preparing his mastiff for a dog show in Carlisle (1978) and several portraits of grandparents with grandchildren speak to us in different ways of the satisfactions available in older age. Franck's desire to collect and display positive images of ageing is an important dimension of her practice as care. Yet she is intent too on social critique and, as we will see in the following section of this chapter, on making visible the unpalatable truths about dependency and isolation in a society that does not prioritise care for those in later life. Such ills above all needed to be documented by the camera, not re-imagined by it in uplifting form. This means that images of decline necessarily form a powerful part of Le Temps de vieillir, contributing to its diversity and integrity.

One of the structural choices in Franck's collection is, however, potentially troubling. I am immediately struck by her decision to reserve the information about each photograph for an appendix. This choice, puzzling at first, means that her subjects as we encounter them are anonymised, decontextualised and hence all the more easily offered up 
less as individuals than as depictions of a common state: old age. Yet I am tempted to turn such an interpretation on its head: we might easily construe the gesture instead as a critique of the ageist gaze, an invitation to look for difference and therefore an integral part of the book's forceful argument for change. The power of Le Temps de vieillir as a thematic collection derives, in my view, from the questions that such undecidability prompts and the ways in which these questions position us. This undecidability includes Franck's skilful shuttling and slippage between image types: documentary images (which we typically think of as holding the spectator at a distance) and portraits (which are, as we know, intended to draw us in). As we leaf through the pages and are buffeted by multiple calls on our imagination, intellect and affect, it is the intimate appeal of the portrait that hovers around each image and persistently engages us. As Graham Clarke notes, the photographic portrait "simultaneously represents the photographic image at its most obvious and yet at its most complex and problematic"; it brings us to ask "precisely what, and who, is being photographed" $(102,101)$; and, most usefully for our purposes here, its boundaries are uncertain. "Perhaps," muses Clarke, "we are entitled to ask at what point an image may be called a portrait" (114; original emphasis). This conundrum will underpin my analyses of specific images from Le Temps de vieillir in the following section.

\section{Photography and Contexts of Care}

Franck's expanded view of and intensive interest in care led her to document the lives of older individuals whose well-being is conspicuously bound up with care facilities, services, institutions and structures. The preface to Le Temps, as well as certain of the photographs within the book, raises the issue of providing adequate support for those who wish to remain in their homes rather than be taken into care, a question which Franck describes as "one of the problems of our civilisation" (Le Temps 14). Throughout her corpus, Franck's photographs of people are typically attentive to the importance of home. Seeing subjects in their daily, domestic environment, surrounded with the artefacts that make ontological sense of who they are, suggests the layered richness of their lives: "I have often photographed people in their homes because I feel that they reveal themselves more in their everyday space, surrounded by their objects" (Le Temps 11). Building on this fascination and on the affective pull of home, her photographs of older people have us shuttle imaginatively between the late-life dilemma of home as healthcare setting and healthcare setting as home. Here I offer short explorations of images which evoke for me particularly powerful responses to this problem and at the same time to Clarke's question about the portrait raised earlier. All of them depict people in institutions or situations of care. All open layers of thinking and feeling about late life, giving a distinctively 
gerontological gloss to Susan Sontag's suggestion that any photograph offers "inexhaustible invitations to deduction, speculation and fantasy" (23). All send me powerfully back to myself, and the more I linger with them, the more it seems to me that rather than constructing a challenge to the ageist look, many of them simply exceed any idea of it.

The caption for a photograph of 93-year-old Mme. Vidal informs us that she lives alone on the sixth floor of a Parisian apartment block without a lift and is no longer capable of going out but is visited several times a week by Accueil et Service [Home Support Services]. These visits, we are told, have "spared her the hospice" (Le Temps 84), although she clearly lives in confinement, and the jumble of decaying domestic objects among which she sits are eloquent on the struggle that is her day-to-day life. A welter of sensory suggestions works powerfully upon me as I meet the sitter's gaze and begin to think into and beyond the frame to entertain the intractable difficulties of her existence. Other photographs which have as subtext the problem of sustaining home invite us to imagine and to care about what this might mean in an institutional setting. Here we feel the tension between an everydayness that the individual has created and one that is created for them. A pair of photographs made in 1975 in the Hospice d'Ivry in the southeastern suburbs of Paris shows how residents have decorated their respective corners of a shared room. In one, Franck empathetically, non-judgementally captures one man's fantasy world, consisting of an array of "girlie" photographs plastered upon the wall above his bed and demarcating his space. In another, an old woman is cocooned by layers of crocheted cushions and other elaborate, handmade artefacts. These are powerful studies suggestive of making home and of seeking to retain self-narrative and memory within institutional contexts. The subjects look awkward within them: the man is de-centred and almost leaving the frame, while the tiny woman appears lost and engulfed in her soft furnishings, her gaze distant. In emotional terms, these still images of home-making are unsettling and put me on the spot in ways that are hard to process and that are medium-dependent: the instantaneous production of such shifting and intense affects is simply unavailable to prose.

As I have suggested, Le Temps de vieillir contains a cluster of images which show Franck's emerging interest in the conditions that prevailed in institutions of "care" (the scare quotes here are deliberate) in 1970s France. Acquiring these images was arduous. Franck notes that she had to wait for four years to be permitted access to the vast and foreboding Maison de Nanterre, one of the largest institutions, and that once there she was permanently accompanied by an intrusive official. Situated in the western suburbs of Paris, the Maison de Nanterre had some 4,800 beds. The scandalously inhumane conditions and brutalising treatment of residents were extensively critiqued by Beauvoir as a core instance of society's neglect in a documentary film made after publication of La Vieillesse, 


\section{Shirley Jordan}

and there is a sense that in her own visit Franck is on the philosopher's trail. ${ }^{12}$ The dominant note in Franck's photographs is social isolation. She observes that in this vast hospice, men and women are segregated not only in the dormitories and canteens but also in the gardens and yards, "where only 'legal' couples are allowed to speak to each other"; it is, she comments, "striking to note the lack of communication between people, who pass by each other without connecting" (Le Temps 86). The implications for mental health are deeply troubling. In one particularly telling photograph, Franck's powerful concern for care patently manifests itself as critique by the way in which she purposefully short-circuits the multiple acts of contact inherent in photography (see Figure 1.1). There is simply no access to the three subjects in this image, just as there is no contact between them. They, and I, remain steeped in a solitude which is difficult to interpret and which pains me. The strong triangular composition, the divergent gazes and the inattentiveness of the women to each other (also to the photographer and hence to us) suggest an aphasic environment. Any opportunity for encounter is denied us by the central figure's turning her back on us, while the other women are differently absorbed, one of them already slipping her way out of the frame. Here the photograph as meeting place - as portraiture - slides into reportage; there is no conduit into the situation or the subjects' inner worlds. They are depicted as (having been made) unreachable.

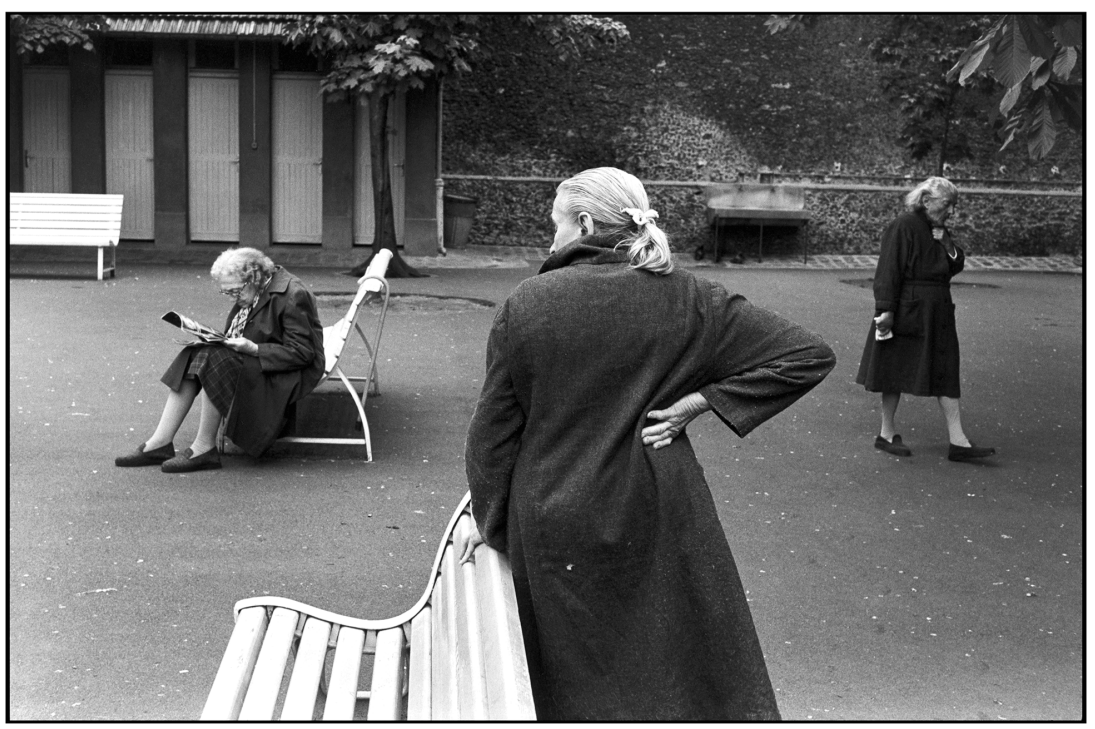

Figure 1.1 Hauts de Seine. "Maison de Nanterre," 1978 (C) Martine Franck/ Magnum Photos. 
Let us turn now to a quite different order of photograph, a powerful declaration of selfhood captured during a protracted encounter in the refectory of the hospice of Ivry-sur-Seine in 1975 (see Figure 1.2). This is clearly not just a portrait, but a portrait with attitude. It has a singular energy and dynamism about it, generated by its subject who controls the image and whose playful, slightly disruptive agency is appealing. She is photogenic. The camera likes her, and her portrait does not connote loneliness or isolation but rather speaks of a rich imaginative life. I am not sure that the photograph pushes age into the "second tier" of my consciousness (Gullette 42); I do not stop seeing the woman's age, but it is far

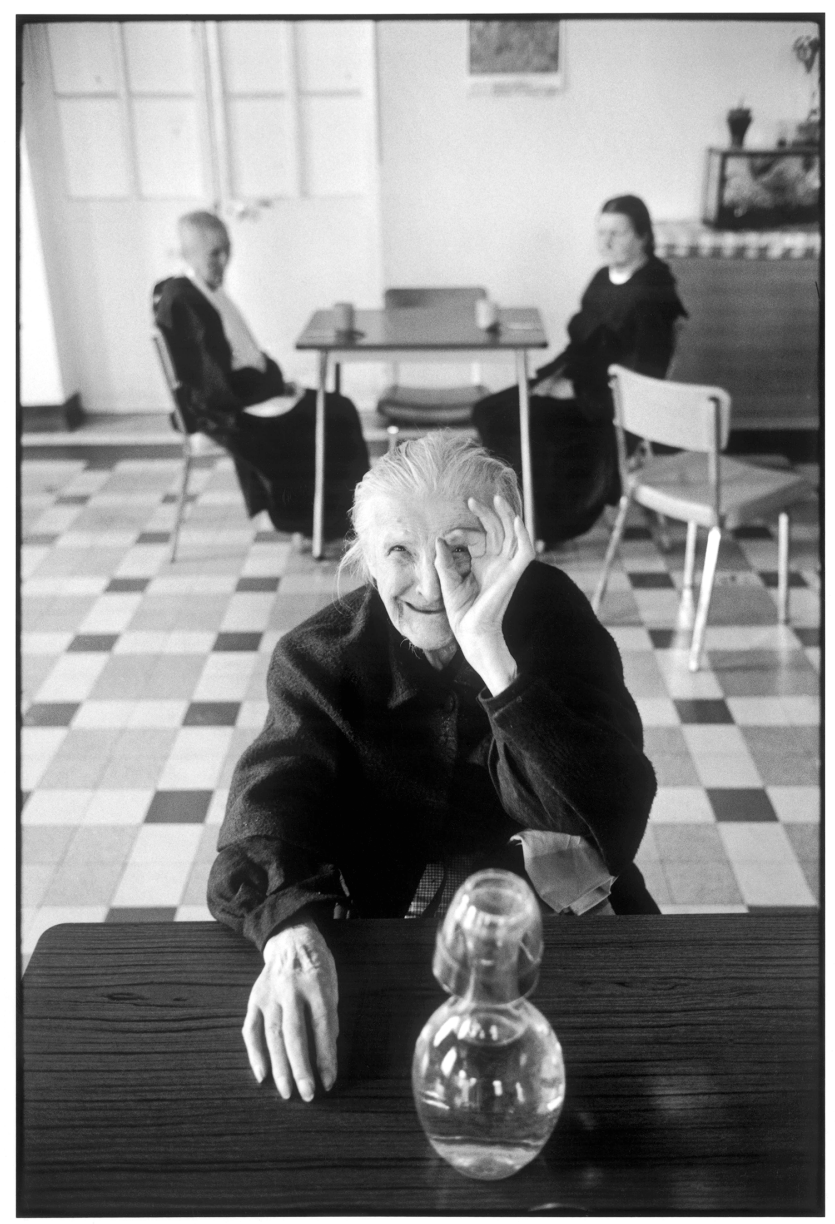

Figure 1.2 Val de Marne. Ivry-sur-Seine. Hospice, 1975 (C) Martine Franck/Magnum Photos. 


\section{Shirley Jordan}

from being all I see. The quality of the intergenerational exchange going on at the moment when the image was taken is energising, unpredictable and exciting; we sense a shared moment of pleasure. The image's composition is rigorous and rich in implications. Its three horizontal bands suggest that the encounter takes place within a Foucauldian power dynamic: the old woman is scrutinised from back and front, sandwiched between the gaze of what appear to be guardians or gatekeepers - shadowy figures whose quiet, regulatory presence is nonetheless confirmed by the way in which they hover in the top band - and that of Franck, alluded to by the indicators of bare hospitality - a table and a carafe of water - in the bottom band. But a more powerful compositional directive is given by the photograph's inverted triangle, all its energy coalescing at the point of encounter. Thus, I am drawn over and over to the woman's strong hand resting on the table and reaching towards Franck, almost breaking the frame.

This portrait is eloquent about the terms of Franck's humanistic practice. Portraiture, she tells us, requires sustained contact, proper listening and "begins with a conversation" (Women/Femmes 90). It is not about asking the subject to pose, but rather to choose how they reveal themselves. Franck prefers to make pictures when communication is, or has been, intense; when her meeting with the other is about something more than the photograph; and when that something more is determined as far as possible by the sitter. Here, the old woman turns the tables on Franck, creating her own lens and looking back in a spontaneous, ludic gesture which implicitly nudges us to ask how we might be seen in return by the older people we are looking at thanks to Franck's lens, as well as reminding us that there is more than one position from which to view the world. If all portraits (barring the selfie) are the result of an encounter, most elide that fact and provide what appears, thanks to one of photography's most invidious sleights of hand, to be uninterrupted access to the subject. This photograph, on the contrary, is about co-presence and a mutual gaze; it depicts an encounter and the terms of that encounter. As for the politics of the exchange, the woman's gesture, while it cannot turn the tables, levels the stakes somewhat. She declares an interest in Franck and in what Franck is doing. In the imaginary lens crafted by her curled thumb and index finger lies, in fact, the stakes of the entire project of Le Temps de vieillir which is to interrogate the structure of the look and learned ways of seeing: who is looking, from what position on the spectrum of age are they looking and how have they learned to see? The image is thus not about decline but about the possibility of vital intergenerational relationships. It alludes to the hope that the result of looking - specifically of looking through a device with a lens - will be to produce a special kind of reciprocal focus, a meeting place. Referring to collections of images of older people, Gullette notes: "I turn such pages languidly, looking for distinctiveness" (29); she would find it in abundance here. 
The final photograph I shall analyse was made in 1980 and is glossed by Franck as follows: "Two sisters who live together in the 13th area of Paris; the Misses Gravin, 82 and 83 years old. The young girl works for "Accueil et Service" and provides care twice a day" (Le Temps 87) (see Figure 1.3). This is a particularly challenging photograph in which the care givers are represented along with the recipient and the burdens that fall upon them implied. It spares us nothing as it presents us with latelife infirmity and vulnerability and valorises the habitually invisible acts of care that are a daily part of life for many older people. Here Franck's exploration and cultivation of care explicitly incorporate "giv[ing] voice and attention to humans who are undervalued precisely because they perform unnoticed, invisible tasks and take care of basic needs" (Laugier 218). We might set this image in dialogue with the first of this collection's close-to-death images, Death of Adam in the opening collage, where Adam begs his son Seth for the oil of mercy, although Franck's is a much more difficult image of dependency, no doubt in part because, although it is painterly, it is not a painting but a photograph. It is one of the most intimate of the book's images and raises the question of what can and what should be photographed, yet without itself seeming intrusive. "Not everything can be photographed," says Franck; "There are moments where suffering, human decline seize you and stop you [while] other situations, even if they are sociologically interesting, may have nothing to say

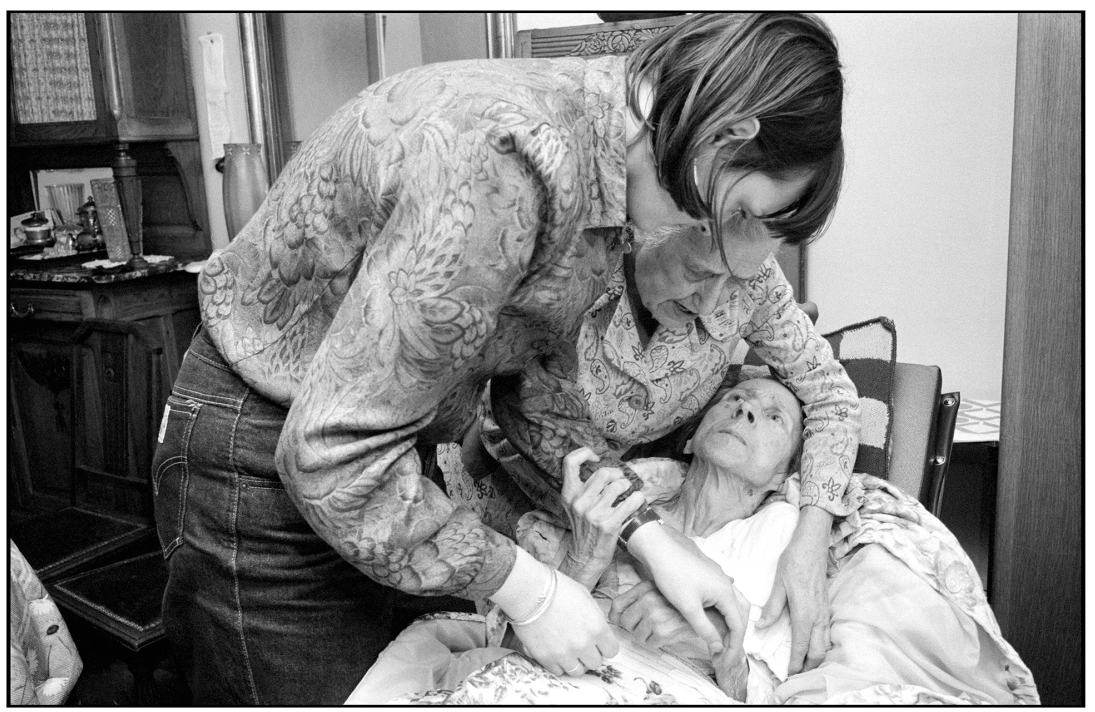

Figure 1.3 Paris. 12ème arrondissement. Association "Accueil et Service," visite à domicile, 1980 @ Martine Franck/Magnum Photos. 
on a visual level" (Le Temps 11). Both the subject matter and the composition of this photograph powerfully raise the question of how we are to look at Franck's images of care, what we might look for within them and what she intends they will prompt.

For me, this photograph occupies a productively troublesome borderland. Am I asked to attend to an idea (that is, an idea of care, documented through a specific act of caring) and a state (illness in late life) or, following the language of portrait photography, to focus on the inner self of the central subject? Referring once more to Clarke's question: is this in any sense a portrait? The question is critical, because if I think not, then I am conceding to view the central figure reductively as representative only of need. I am reminded - although the category of photograph is very different - of the difficult debates generated by the portraits that Richard Avedon made of his father in the last stages of a terminal illness, debates around intrusiveness, ethics and aesthetics. Here the moving, intense choreography of interlocking bodies and gazes, confirming that the self is always in the hands of others, gives value to the activity in train; yet there is also insistence on the experience and the inner world of the central figure. I am caught on the cusp between my immediate reaction to the photograph as document and an urgent call to feel my way more deeply into the picture's experiential dimension; to ask the right kinds of questions of it and of myself. What Franck offers us here is a singularly heightened photograph of care, which also dignifies care. "As a concept," remarks Alessandro Pratesi, "care encompasses both instrumental tasks and affective relations, ranging from activity to ethics, that is, from 'taking charge' of others' physical well-being to 'feeling concern' for others' physical and psychological well-being" (96; original emphasis); all of these dimensions of care are captured here by Franck. Not only does her photograph valorise the gestures and what Lisa Baraitser has called the "stuck" time of care (time marked by "unprofitable" acts of "waiting, staying, delaying, enduring, returning" [14], so out of kilter with the urgent acceleration that has become life's normative pace), it also transposes everyday gestures into an image of powerful symbolic value. It is consistent with the suggestion of ethical theorist Annette Baier that we bring to the fore of our ethical considerations qualities such as gentleness (219) and, returning to Laugier, that we take on board the routine physicality of care: "care [as] a practice, not 'only' a moral feeling or disposition" (226). It has extraordinary gravity and a pronounced dramatic dimension. It emphasises what binds us as we care: the touch and the gaze. As I lean in to scrutinise the cluster of bodies and faces, I know that there is a potential for voyeurism, but Franck is ever tactful, unthreatening and discreet. The image's strong composition binds together form and content in a powerful example of how Franck's sociological, humanitarian purpose was served by the drive to formal experimentation and stringent aesthetic criteria which she rarely sacrificed. This photograph of an explicit act 
of care constitutes in itself an act of care as it takes us to an extreme of empathy: transfixed at the bonds in evidence in this urgent knot of bodies, my identification shuttling between the web of relationships that they imply, I know as I transfer my gaze to the central figure that I am looking, potentially, at myself.

Although she did not articulate it in these terms, it seems to me that the multiple encounters to which Franck invites us in Le Temps de vieillir, encounters which repeatedly test what empathy theorist Kathryn Robson has referred to as "the grammar of location and distance that structures and shapes relations of empathy and compassion" (693), are intended to lock us in to a view of social relations as organised around dependency and vulnerability and thus to have us measure the importance of care for human life. Such recognition entails, as feminist theorists of care have noted, understanding that dependence and precariousness are not accidents that happen only to others. Although Beauvoir divided $\mathrm{La}$ Vieillesse into two parts - first, older people seen from outside their world as objects of knowledge; second the view of self, time and world from within - Franck's every image keeps us profitably snagged between these two perspectives, effectively reminding us that, as Judith Butler so neatly observes, "dependency fundamentally defines us" (33). Thus, it is on the common terrain of vulnerability, captured by the lens, that Franck's photographs of older people address the imperative so powerfully articulated in Beauvoir's La Vieillesse: "We must stop cheating: the whole meaning of our life is in question ... let us recognize ourselves in this old man or that old woman" (5).

\section{Legacies}

Franck's Le Temps de vieillir launched her reputation as a major photographer, led to her intensive work with Les petits frères des Pauvres and constituted the first stage in her production of one of the most extensive photographic records of the lives of older people to exist anywhere in the world. How can we explain, then, that the current chapter is the only critical assessment to date of what surely constitutes a major landmark in cultural gerontology ${ }^{13}$ Here we might return to connect Franck with Beauvoir once more, for in spite of favourable views upon its publication, La Vieillesse was also until recently largely ignored, "neglected by feminists, humanists, gerontologists, historians and philosophers alike" (Katz n.p.). Thus, a quietly consensual side-lining of two courageous and extraordinary endeavours to change perceptions of older people demonstrates the enduring validity of the very critique that propelled both philosopher and photographer into action in the first place. It is only in recent years that serious engagements with Beauvoir's La Vieillesse have emerged and that it has been brought to prominence again, largely by feminist scholars of ageing. ${ }^{14}$ It is time to revisit Franck's work in 


\section{Shirley Jordan}

the same way and, putting an end to three decades of critical neglect, to situate it firmly within the evolving histories of cultural and visual gerontology. This chapter has made a start. In particular, I have argued that Franck's relentless attempt to re-educate society's gaze and to reinstate older people and our relationships with them in the visual field anticipates the emphasis on care with which we are today becoming so familiar, and seeks to make of care ethics a "politics of the ordinary" (Laugier). It is the powerful connection between Franck's work as praxis and contemporary theories, practices and imaginaries of care which, in my view, deserves wider scholarly enquiry.

\section{Notes}

1. Martine Franck, Le Temps de vieillir. Journal d'un Voyage - 4 (Paris: Filipacchi-Denoël, 1980). Franck's books are not translated. Translations in this chapter are my own.

2. It is worth noting that Franck's work intersects with gender studies and disability studies as well as ageing studies. She promoted a range of causes, from women's rights to the deprivations of children with disabilities, and was deeply committed to working within marginal communities. Her powerful respect for others thus establishes her practice as one that is generally driven by ethical issues and the challenges of care, although I contend that care manifests itself in distinctive ways where her photographs are of older people.

3. I do not seek to develop in this chapter a specifically feminist argument, but my appreciation of Franck's moral sensibility is certainly in tune with the connection that many care theorists draw between women's intimate understanding of marginalisation and the development of care ethics. See, for instance, Gilligan, "Moral Orientation"; Kittay and Feder; Koehn; Tronto and Fisher.

4. "For women, old age weighs heavy and the risks of solitude are greater" (Franck, Le Temps 11).

5. Some of this work is collected in Martine Franck, De temps en temps.

6. Publication of the book was followed by an exhibition entitled Le Temps de vieillir, shown at the Musée Nicéphore Niépce in Châlon-sur-Saône (1981), and the Malmö Museum in Sweden (1982).

7. Though some of the photographs pre-existed the commission, most were taken close to the year of publication and in direct response to the challenge. It was this commission that launched Franck's career as a photographer of ageing subjects and documenter of the provision of care, both formal and informal.

8. Cameron made numerous photographs of older people and was a strong influence on Franck.

9. I have to date been unable to discover whether Franck conversed directly with Beauvoir about her work on ageing, although the two women attended many of the same women's rights events in 1970s France, with Franck documenting some of these, so the opportunity was certainly there.

10. "just before I come back to reality, a giant beast settles on my breast: 'It's true! It's my nightmare of being more than fifty that's come true!' " (Beauvoir, Force of Circumstance 656).

11. I am thinking of Waring's Rock ' $n$ ' Roll 70 Wallpaper (2019) and Sherman's portraits of herself as ageing screen stars from the Golden Age of cinema (2016). 
12. This harrowingly frank documentary, PROMENADE AU PAYS DE LA VIEILLESSE / A WALK IN THE COUNTRY OF OLD AGE (1974) was made by Marianne Ahrne in the hospices at Ivry and Nanterre. For an account of the film, see Oliver Davis, Age Rage and Going Gently: Stories of the Senescent Subject in Twentieth-Century French Writing (164-9 and 197-204). Ahrne notes that Beauvoir had not been granted access to Nanterre and had not been to Ivry while researching The Coming of Age (201).

13. There exists one other piece, "Martine Franck au pays de la vieillesse," a largely descriptive tribute penned by Michel Christolhomme, then Director of Les petits frères des Pauvres, shortly after Franck's death.

14. See in particular Silvia Stoller (ed.), Simone de Beauvoir's Philosophy of Age: Gender, Ethics and Time. de Gruyter, 2014.

\section{Works Cited}

Baier, Annette. Postures of the Mind: Essays on Mind and Morals. U of Minnesota P, 1985.

Baraitser, Lisa. Enduring Time. Bloomsbury, 2017.

Baring, Louise. Martine Franck. Phaidon, 2007.

Beauvoir, Simone de. Force of Circumstance. Penguin, 1968.

- La Vieillesse (Gallimard, 1970); The Coming of Age. Translated by Patrick O'Brian. Putnam, 1972.

Butler, Judith. "On Cruelty.” London Review of Books, vol. 36, no. 14, 2014, pp. 31-3.

Christolhomme, Michel. "Martine Franck au pays de la vieillesse." Gérontologie, vol. 164, Nov. 2012, pp. 26-43.

Clarke, Graham. The Portrait in Photography. Reaktion Books, 1992.

Davis, Oliver. Age Rage and Going Gently: Stories of the Senescent Subject in Twentieth-Century French Writing. Rodopi, 2006.

Dyer, Geoff. The Ongoing Moment. Canongate Books, 2012.

Franck, Martine. Les Lubérons. Éditions du Chêne, 1978.

- Le Temps de vieillir: Journal d'un Voyage - 4. Filipacchi-Denoël, 1980.

- De temps en temps. Trois-Cailloux Éditions, 1988.

- One Day to the Next. Thames and Hudson, 1998.

- Women/Femmes. Steidl, 2010.

Gilligan, Carol. In a Different Voice. Harvard UP, 1982.

- "Moral Orientation and Moral Development." Justice and Care: Essential Readings in Feminist Ethics. Edited by Virginia Held. Westview Press, 1995, pp. 31-46.

Gullette, Margaret Morganroth. Ending Ageism or How Not to Shoot Old People. Rutgers UP, 2017.

Harris, Mark Edward. The Travel Photo Essay: Describing a Journey through Images. Routledge, 2018.

Katz, Stephen. "Simone de Beauvoir's The Coming of Age: The Humanities and Gerontology's Diagram of Science.” Age Culture Humanities, vol. 3, 2016, ageculturehumanities.org/WP/simone-de-beauvoirs-the-coming-of-age-thehumanities-and-gerontologys-diagram-of-science/.

Kittay, Eva Feder, and Ellen K. Feder, editors. The Subject of Care: Feminist Perspectives on Dependency. Rowan and Littlefield, 2002. 


\section{Shirley Jordan}

Koehn, Daryl. Rethinking Feminist Ethics: Care, Trust and Empathy. Routledge, 1998.

Koggel, Christine M., and Joan Orme, editors. Care Ethics: New Theories and Applications. Routledge, 2015.

Laugier, Sandra. "The Ethics of Care as a Politics of the Ordinary." New Literary History, vol. 46, no. 2, 2015, pp. 217-40.

Meagher, Michelle. "Art, Ageing and the Body." Routledge Handbook of Cultural Gerontology. Edited by Julia Twigg and Wendy Martin. Routledge, 2015, pp. 85-92.

Mitchell, W. J. T. What do Pictures Want? The Lives and Loves of Images. U of Chicago P, 2006.

Pratesi, Alessandro. "The Productivity of Care: Contextualising Care in Situated Interaction and Shedding Light on its Latent Purposes." Care Ethics: New Theories and Applications. Edited by Christine M. Koggel and Joan Orme. Routledge, 2015, pp. 94-108.

Robson, Kathryn. "The Limits of Empathy and Compassion in Delphine de Vigan's No et moi and Les Heures souterraines." Modern Language Review, vol. 110, no. 3, 2015, pp. 677-93.

Sontag, Susan. On Photography. Penguin, 1977.

Stoller, Silvia, editor. Simone de Beauvoir's Philosophy of Age: Gender, Ethics and Time. de Gruyter, 2014.

Tronto, Joan, and Berenice Fisher. "Towards a Feminist Theory of Caring." Circles of Care: Work and Identity in Women's Lives. Edited by Emily Abel and Margaret Nelson. SUNY Press, 1990.

Woodward, Kathleen. "Performing Age, Performing Gender." NWSA Journal, vol. 18 , no. 1,2006 , pp. 162-89. 